\title{
IMPLEMENTASI HUKUM ISLAM DALAM PEMIKIRAN MU'TAZILAH
}

\author{
Muliati \\ Sekolah Tinggi Agama Islam Negeri (STAIN) Parepare \\ Email: sesady.muliati@gmail.com
}

\begin{abstract}
In modern times and the advancement of science and technology, the rational Mutazilah teachings have begun to re-emerge among Muslims especially among the intelectual counity. Unknowingly they have had the same or close understandings of the Mutazila teachings. Having such ideals does not exclude them from Islam.
\end{abstract}

Abstrak:. Di zaman modern dan kemajuan ilmu pengetahuan dan teknologi, ajaran-ajaran Mutazilah yang bersifat rasional itu telah mulai muncul kembali di kalangan umat Islam terutama di kalangan kaum terpelajar. Secara tak sadar mereka telah mempunyai paham-paham yang sama atau dekat dengan ajaran-ajaran Mutazilah. Mempunyai paham-paham yang demikian tidaklah membuat mereka ke luar dari Islam.

Kata Kunci: Hukum Islam, Mu’tazilah, Teologi

\section{PENDAHULUAN}

Agak aneh kiranya kalau dikatakan bahwa dalam Islam, sebagai agama, persoalan yang pertama-tama muncul adalah dalam bidang politik dan bukan dalam bidang teologi. Tetapi persoalan politik ini segera meningkat menjadi persoalan teologi. Agar hal ini menjadi jelas perlulah kita terlebih dahulu kembali sejenak ke dalam sejarah Islam, tegasnya ke dalam fase perkembangan yang pertama, khususnya masa pemerintahan Ali bin Abi Talib.

Pertempuran yang terjadi dikenal dengan perang Siffin. Perang ini diakhiri dengan tahkim (arbitrase), tapi tahkim ternyata tidak menyelesaikan masalah, bahkan menyebabkan timbulnya golongan ketiga, al-Khawarij, orang-orang yang keluar dari barisan Ali. Akibatnya di ujung pemerintahan Ali bin Abi Thalib, umat Islam terpecah menjadi tiga kekuatan politik, yaitu Muawiyah, Syi'ah dan Khawārij, inilah cikal bakal lahirnya paham-paham dalam Islam.

Setelah Usman wafat, masyarakat beramai-ramai membaiat Ali bin Abi Thalib sebagai khalifah. Ali memerintah hanya enam tahun. Selama masa pemerintahannya ia menghadapi berbagai pergolakan. Tidak ada sedikitpun masa pemerintahan dapat dikatakan stabil, setelah menduduki jabatan khalifah, Ali memecat para gubernur yang diangkat oleh Usman. Dia juga 
menarik kembali tanah yang dihadiahkan Usman kepada negara, dan memakai kembali sistem distribusi pajak tahunan di antara orang-orang Islam sebagaimana pernah ditetapkan Umar.

Ali bin Abi Thalib menghadapi pemberontakan Thalhah, Zubair, dan Aisyah. Alasan mereka, Ali tidak mau menghukum para pembunuh Usman dan mereka menuntut bela terhadap darah Usman yang telah ditumpahkan secara zalim. Ali sebenarnya ingin menghindari perang. Dia mengirim surat kepada Thalhah dan Zubair agar mau berunding untuk menyelesaikan perkara itu secara damai. Namun ajakannya ditolak. Akhirnya terjadilah pertempuran yang dikenal dengan perang Jamal. (Unta). Zubair dan Thalhah terbunuh dan Aisyah ditawan dan dikirim kembali ke Madinah.

Selesai perang Jamal, Ali harus menghadapi aksi makar dari Muawiyah ibn Abi Sufyan yang menuntut agar segera menindak terhadap pembunuh Usman ibn Affan dan meminta 'Alī lengser dari jabatan khalifah. Aksi makar itu muncul karena sebelumnya 'Alī memecat Muawiyah dari jabatan Gubernur Syiria. Akibat teror yang terus menerus dilakukan Muawiyah, 'Alī beserta pasukannya memeranginya di daerah Siffin, Irak.
Akibat bersikeras Muawiyah yang tidak bisa diajak berdamai, maka Ali memeranginya. Dalam pertempuran itu, Pasukan Muawiyah mulai melemah dan mendekati kekalahan. Melihat tanda-tanda kekalahan akan menimpanya, penasihat Muawiyah ibn Abi Sufyan yang bernama Amr ibn Ash menyarangkan untuk melakukan perundingan dengan terlebih dahulu mengangkat lembaran mushaf Al-Qur'an.

Melihat pasukan musuh mengangkat mushaf Al-Qur'an, sebagian pengikut Ali terpengaruh sehingga memintanya agar menerima tawaran tahkim. ${ }^{1}$ Ali mengetahui itu sebagai tipu muslihat, sehingga tidak meresponnya. Ali malah terus menyemangati pasukannya. Ali mengatakan, saya lebih tahu dari pada kalian, saya mengetahui mereka dari kecil sampai dewasa, mereka adalah anak-anak dan lakilaki dewasa yang jelek. Mereka meminta untuk ber-tahkim kepada kitab Allah padahal, demi Allah mereka mengangkat mushaf itu hanyalah untuk tipu muslihat saja, ujar 'Alī. 2

Namun desakan dari Mis'ar Fadki At-Tamimi, Zaid Husain Ath-Thai, dan para ahli qura ${ }^{3}$ dalam pasukan Ali terus mendesak dan mengancam akan meperlakukan Ali bin Abi Thalib seperti yang terjadi pada Utsman ibn Affan. Dengan terpaksa 'Alī 
mengikuti permintaan mereka.

Muawiyah mengutus Amr ibn Ash sebagai juru runding dan Abū Musa al-Asy'arī mewakili pihak Ali bin Abi Thalib. Keduanya melakukan perundingan di Daumah Al-jandal, selama enam bulan (Shafar-Ramadhan $37 \mathrm{H}$ ). Persoalan yang dibahas adalah tuntutan atas kematian Usman ibn Affan dan juga dibahas untuk menyatukan umat Islam dengan terlebih dahulu menurunkan kedua pimpinan Islam yang bertikai dan mengangkat pimpinan umat Islam dengan jalan musyawarah.

Atas dasar senioritas, Abu Musa menjadi orang pertama yang naik kemimbar dan menurunkan Ali dari tampuk khalifah Islam. Kemudian, Amr ibn Ash dengan tanpa diduga langsung mengukuhkan Muawiyah sebagai khalifah Islam tanpa menurunkannya terlebih dahulu, hal ini mengecewakan bagi pendukung Ali bin Abi Thalib.

Pertempuran yang terjadi dikenal dengan perang Siffin. Perang ini diakhiri dengan tahkim (arbitrase), tapi tahkim ternyata tidak menyelesaikan masalah, bahkan menyebabkan timbulnya golongan ketiga, al-Khawārij, orang-orang yang keluar dari barisan 'Alī. Akibatnya di ujung pemerintahan Ali bin Abi Thalib umat Islam terpecah menjadi tiga kekuatan politik, yaitu Muawiyah, Sȳ̄'ah dan Khawārij, inilah cikal bakal lahirnya paham-paham dalam Islam.

Pergolakan yang terjadi pada masa pemerintahan Khulafaur Rasyidin ini memberikan konstribusi terhadap terbentuknya kelompok-kelompok paham keagamaan yang masing-masing menganggap kelompok mereka yang paling berkuasa dan benar dalam memahami dan mempraktekkan ajaran Islam. Dalam agama Islam di kenal adanya paham-paham atau firqahfirqah antara lain: Syi'ah, Khawarij, Murji'ah, Mu'tazilah, Qadarīyah, Jabariyah ,Asy'ariyah, Maturidiyah, dan Ahlusunnah wal Jamaah. Firqah bisa diartikan sekte.

Berdasarkan uraian latar belakang di atas, maka yang menjadi rumusan masalah pokok dalam kajian ini adalah Paham Mu'tazilah.

\section{PEMBAHASAN}

\section{A. Sejarah Lahir Mu'tazilah}

Aliran Mu'tazilah adalah aliran pikiran Islam yang terbesar dan tertua, yang telah memainkan peranan yang sangat penting orang yang hendak mengetahui filasafat Islam yang sesungguhnya dan berhubungan dengan agama dan sejarah pemikiran Islam haruslah menggali buku-buku yang dikarang Mu'tazilah, bukan yang dikarang oleh orang-orang yang lazim disebut filosof Islam, seperti Ibnu Sina dan Ibnu Rusydi. ${ }^{4}$ 
Kaum Mu'tazialah adalah golongan yang membawa persoalan-persoalan teologi yang lebih mendalam dan bersifat filosofis daripada persoalanpersoalan yang dibawa kaum Khawarij dan Murjiah. Dalam pembahasan banyak memakai akal sehingga mereka mendapat nama "kaum Rasionalis Islam, 5

Kaum Mu'tazilah adalah golongan yang membawa persoalan-persoalan teologi yang lebih mendalam dan bersifat filosofis dari pada persoalanpersoalan yang dibawa kaum Khawārijdan Murji'ah. Dalam pembahasan, mereka banyak memakai akal sehingga mereka mendapat nama "kaum rasionalisme Islam". ${ }^{6}$ Perkataan $\mathrm{Mu}$ 'tazilah berasal dari kata $i$ 'tazala, artinya menyisihkan diri. Berbeda pendapat orang tentang sebab-musabab timbulnya firqoh Mu'tazilah itu.

\section{Dinamakan} $\mathrm{Mu}$ 'tazilah, memisahkan berlainan pendapat dengan gurunya Al-hasan al-Bisri, tentang masalah orang Islam yang melakukan dosa besar, yang belum taubat sebelum meninggal. Golongan ini sendiri tidak mau dinamakan $\mathrm{Mu}$ 'tazilah, mereka mengakui dirinya golongan pembela keadilan dan ketauhidan. ${ }^{7}$

Versi lain menjelaskan, seorang ulama tabi'in yang terkenal bernama Imam Hasan al-
Basri (w. $110 \quad$ H) yang menyelenggarakan majelis pengajarannya di masjid kota Basrah. Di antara muridnya yang terbilang pandai ialah Wașil ibn Ața' (w. 131 H) Suatu hari Imam Hasan al-Basri ini menerangkan bahwa seorang Islam yang telah beriman kepada Allah swt., dan Rasulnya, kemudian orang itu melakukan dosa besar, lalu orang itu meninggal sebelum bertaubat, menurut Imam Hasan al-Basri orang itu tetap muslim. Hanya saja Muslim yang durhaka (ma'șiyat). Di akhirat kelak, dia dimasukkan kedalam neraka untuk sementara waktu guna menerima hukuman atas perbuatan dosanya itu. Sampai batas tertentu sesudah menjalani hukuman itu dia dikeluarkan dari neraka, kemudian dimasukkan dalam surga. ${ }^{8}$

Versi lain menjelaskan bahwa Mu'tazilah lahir pada awal pemerintahan klalifah keempat, 'Alīibn Abi Ṭālib, tidak semua sahabat senior yang tinggal di Madinah mendukung kekhalifaan 'Alī. Diantara mereka adalah Talhah ibn Ubaidillah, Zubair ibn Marwan, Sa'ad ibn Abi Waqqas, Abdillah ibn Umar dan Zaid ibnśabit, Talhah dan Zubair terang-terangan memberontak terhadap 'Alī, sedangkan yang lain bersifat netral. Penduduk Madinah pada umumnya, dan sebagian dari penduduk Tamimi, mengikuti sikap netral tersebut, meskipun 
tidak memusuhi 'Alī tetapi tidak memihak memusuhi 'Alī, seperti Muawiyah. ${ }^{9}$

Pada awal abad II $\mathrm{H}$ muncul $\mathrm{Mu}$ 'tazilah dalam paham teologi, ialah ketika terjadi perselisihan pendapat antara Wașil ibn Ața', seorang alim di Bashrah, dan gurunya, ahli fiqih Hasan Basri, tentang penilaian terhadap seorang mukmin yang telah berbuat banyak dosa: apakah dia masih dapat dinamakan seorang mukmin atau tidak, menurut Hasan Basri seorang mukmin yang demikian itu dapat disebut seorang munafik, sedangkan bagi Wașil orang tersebut tidak mungkin lagi disebut mukmin, tetapi tidak pula dikatakan kafir. Dia hanya ditempatkan pada posisi antara mukmin dan kafir (manzilah baina al-Manzilatain). ${ }^{10}$

Dari beberapa versi yang menjelaskan tentang asal-usul lahirnya $\mathrm{Mu}$ 'tazilah ini. Pada intinya secara umum munculnya paham ini berlatar belakang tentang perbedaan pendapat antara Wașil ibn Ața dengan gurunya Hasan Basri yang berkaitan dengan dosa besar, penilaian terhadap status seorang mukmin yang telah melakukan dosa besar dan posisi/tempat orang yang melakukan dosa besar, apakah dia masih dikatakan mukmin atau tidak. Menurut Hasan Basri seorang mukmin yang demikian itu disebut munafik, sedangkan
Wașil ibn Ața orang tersebut tidak mungkin disebut mukmin, tidak juga dikatakan kafir, dia hanya ditempatkan pada posisi mukmin dan kafir (manzilah baina alManzilatain).

Hal yang membedakan Mu'tazilah dengan aliran teologi Islam lainnya adalah pemahamannya yang lebih banyak mempergunakan dalil-dalil rasional dan bersifat filosofis. Sehingga wajar bila $\mathrm{Mu}^{\prime}$ tazilah dikenal sebagai pengusung teologi rasional. Mereka lebih meninggikan kedudukan akal ketimbang wahyu. Dalam memahami Al-Qur'an pun mereka meninggalkan arti harfiah teks. Mereka hanya mengambil makna simbol teks dengan metode ta'wīl. Menurut Mu'tazilah Al-Qur'an adalah kalam Allah tersusun dari suara dan huruf-huruf, yang juga makluk karena diciptakan Allah, sesuatu yang diciptakan adalah bersifat baru dan tidak qadim. Jika seseorang mengatakan bahwa AlQur'an itu qadim, ia musyrik karena berpendapat ada yang qadim selain Allah. Pandangan mereka kepada hadis sama dengan pandangan mereka terhadap AlQur'an Mereka tidak mau menerima hadis yang bersumber dari muhaddis yang berbeda pendapat dengan $\mathrm{Mu}$ 'tazilah.

$\mathrm{Mu}$ 'tazilah memiliki pemikiran yang khas perihal ketaatan dan hubungan manusia 
dengan Allah. Menurut kalangan Mu'tazilah, semua perintah Allah adalah benar adanya dan sifat benar terpisah dari perintah Allah. Agama memang berperan dalam menyediakan aturan dan menunjukkan bagaimana seharusnya manusia melaksanakannya, tapi benar tidaknya pelaksanaan tersebut ditentukan oleh pelakunya sendiri (manusia). Karena itu Allah harus memberi pahala semua perbuatan baik. Jika tidak memberi pahala, berarti Allah berbuat tidak adil.

Keberadaan aliran $\mathrm{Mu}^{\text {'tazilah }}$ mendapat dukungan dari penguasa Daulah Abbasiyah, yaitu khalifah Al-Ma'mun (98-218H/813-833 M) kemudian mengukuhkan sebagai mazhab resmi negara. Dukungan penguasa itu dimamfaatkan oleh Mu'tazilah untuk memaksakan ajarannya kepada aliran-aliran Islam lainnya, yang dikenal dengan peristiwa mihnah (inkuisisi). Khalifah Al-Ma'mun menginstruksikan untuk mengadakan pengujian (fit and proper test) terhadap aparat pemerintah tentang keyakinan mereka akan paham $\mathrm{Mu}$ 'tazilah, namun dalam pelaksanaannya, tidak hanya aparat pemerintah yang diperiksa, tetapi juga tokohtokoh Islam lainnya. ${ }^{11}$

Mereka yang tidak sepaham dengan $\mathrm{Mu}^{\prime}$ tazilah disiksa dan dijebloskan ke penjara. Iman Ahmad ibn Hambal disiksa dan dipenjara karena tidak mengakui kemahlukan Al-Qur'an. Juga ada yang dibunuh seperti Al-Khuzzai dan Al-Buwaiți.

Konsepsi politik Mu'tazilah pada umumnya menengaskan bahwa imamah atau kepemimpinan negara itu merupakan pilihan rakyat, karena Allah tidak memberikan penegasan tentang siapa yang harus memimpin umat sepeninggal Nabi, yang sesuai dengan firman dalam surat Al-Hujurat ayat 13 yang menyatakan bahwa "yang termulia di antara kita bagi Allah adalah yang paling bertaqwa", maka hak menjadi khalifah tidak merupakan hak istimewa bagi suatu keluarga atau suku tertentu. $^{12}$ Bagi Mu'tazilah hak memilih kepala negara diserahkan kepada rakyat sepenuhnya, yang kemudian mengangkatnya untuk melaksanakan hukum, tanpa memandang suku. Apakah dari suku Quraisy atau bukan, asalkan beragama Islam, mukmin yang adil, serta tidak membedakan diantara suku.

\section{B. Tokoh-Tokoh Mu`tazilah}

Gerakan kaum Mu’tazilah pada mulanya memiliki dua cabang yaitu :

1. Di Basrah (Iraq) yang dipimpin oleh Washil Ibn Atha' dan Amr Ibn Ubaid dengan murid-muridnya, yaitu Ustman bin Ath Thawil, Hafasah bin Salim dll. Ini berlangsung pada permulaan abad 
ke $2 \mathrm{H}$. Kemudian pada awal abad ke $3 \mathrm{H}$ wilayah Basrah dipimpin oleh Abu Huzail Al-Allah (wafat 235), kemudian Ibrahim bin Sayyar $(211 \mathrm{H})$ kumudian tokoh Mu tazilah lainnya.

2. Di Bagdad (iraq) yang dipimpin dan didirikan oleh Basyir bin AlMu tamar salah seorang pemimpin Basrah yang dipindah ke Bagdad kemudian mendapat dukungan dari kawan-kawannya, yaitu Abu Musa Al- Musdar, Ahmad bin Abi Daud dll. Inilah imam-imam Mu`tazilah di sekitar abad ke 2 dan ke 3 H. Di Basrah dan di Bagdad, khalifahkhalifah Islam yang terang-terangan menganut dan mendukung aliran ini adalah:

1) Yazid bin Walid (Khalifah Bani Umayyah yang berkuasa pada tahun 125-126 $\mathrm{H}$ )

2) Ma`mun bin Harun Ar-Rasyid (Khalifah Bani Abbasiah 198$218 \mathrm{H})$

3) Al- Mu`tashim bin Harun ArRasyid (Khalifah Bani Abbasiah 218-227 H)

4) Al- Watsiq bin Al- Mu'tashim (Khalifah Bani Abbasiah 227$232 \mathrm{H})^{13}$.

Diantara golongan ulama Mu`tazilah lainya adalah :

1) Utsman Al- Jahidz, pengarang kitab Al- Hewan (wafat 255 $\mathrm{H})$

2) Syarif Radhi $(406 \mathrm{H})$

3) Abdul Jabbar bin Ahmad yang terkenal dengan sebutan Qadhi`ul Qudhat.
4) Syaikh Zamakhsari pengarang tafsir Al- Kasysyaf (528)

5) Ibnu Abil Hadad pengarang kitab Syarah Nahjul Balaghah (655)

\section{Pokok Ajaran Mu'tazilah}

Pokok-pokok Ajarannya yang dikenal dengan al-usul al-khamsah (lima dasar) yang harus menjadi pegangan sekaligus identitas bagi kaum Mu'tazilah. Kelima dasar atau ajaran Mu'tazilah ini adalah merupakan pengembangan yang dilakukan oleh murid-murid atau pengikut-pengikut terhadap Wasil ibn 'Atha' setelah melalui proses modifikasi terhadap unsur lain maka lahirlah ajaran dasar dan baku bagi aliran Mu'tazilah yang dikenal dengan al-Usul al-khamsah, sedang Wasil ibn'Atha' sebagai pendiri aliran ini telah meletakkan tiga ajarannya sebagai dasar pertama dalam bidang teologi, yaitu Nafi al-Sifat, Qadar dan al-Manzilah bain al-Manzilatain 14 Namum dua ajaran di antaranya merupakan warisan dari Wasil ibn 'Atha yaitu al-Tauhid, sebagai materi intinya adalah penjagaan sifat-sifat Allah (Nafi al-Sifat) dan al-Manzilah bain almanzilatain dengan topik pembahasannya adalah stasus orang yang telah berbuat dosa besar.

Kelima dasar itu adalah:

1) Tauhid (pengesaan)

Tauhid adalah dasar ajaran Islam yang pertama dan utama. Sebenarnya ajaran tauhid ini bukan monopoli Mu'tazilah saja, tetapi ia menjadi milik setiap 
orang Islam. Hanya saja Mu'tazilah mempunyai tafsir yang khusus dan mereka mempertahankannya, sehingga mereka menamakan dirinya sebagai Ahlul 'Adli Wa al-Tauhid.

Doktrin Mu'tazilah
mengatakan bahwa tidak ada satu pun yang dapat menyamai Tuhan. Begitu pula sebaliknya, Tuhan tidak serupa dengan mahlukNya. Tuhan adalah immateri, oleh karena itu tidak layak bagiNya setiap atribut materi. Segala yang mengesankan adanya kejiziman Tuhan, bagi Mu'tazilah, tidak dapat diterima oleh akal, dan itu adalah mustahil. Maha suci Tuhan dari penyerupaan tuhan dengan mahlukNya. Tegasnya Mu'tazilah menolak antroporfisme. ${ }^{15}$

Penolakan terhadap faham Antropomorfisme bukan sematamata atau pertimbangan akal, melainkan memiliki rujukan yang sangat kuat di dalam Al-Qur'an surah Asy-Syura, 42:

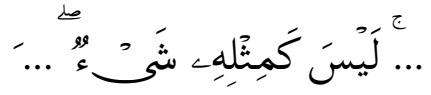

Terjemahnya:

Tidak ada sesuatupun yang serupa dengan Dia. ${ }^{16}$

\section{2) Al-adl (keadilan)}

Keadilan berarti meletekkan tanggung jawab manusia atas perbuatan-perbuatannya. Tuhan tidak menghendaki keburukan, tidak menciptakan perbuatan manusia, manusia bisa mengerjakan perintah-perintah-
Nya dan meninggalkan laranganlarangan-Nya, karena kekuasaan dijadikan Tuhan pada diri manusia.

3) Wa'ad wal wa'id (janji dan ancaman)

Tuhan berjanji akan memberi pahala dan mengancam akan memberikan siksaan, pasti dilaksanakan, karena Tuhan sudah menjanjikan demikian. Siapa yang berbuat baik maka dibalas dengan kebaikan dan sebaliknya mereka yang berbuat kejahatan akan dibalas dengan kejahatan pula. Tidak ada ampunan bagi orang yang melakukan dosa besar tanpa tobat, sebagaimana tidak mungkin orang yang berbuat baik tidak menerima pahala.

4) Al-Manzilah baina almanzilatain (tempat diantara dua tempat).

Ajaran yang dibawa Wașil bin Ata', tempat diantara dua tempat dalam arti tempat menengah. Menurut ajaran ini orang yang berdosa besar bukan kafir, sebagai disebut kaum Khawārij, dan bukan pula mukmin sebagai dikatakan Murji'ah, tetapi fasiq yang menduduki posisi di antara posisi mukmin dan kafir.

Versi lain menjelaskan $A l$ Manzilah baina al-manzilatain (tempat diantara dua tempat). Karenanya Wașil bin Ata' memisahkan diri dari Hasan Basri. Wasil memutuskan bahwa 
orang yang berbuat dosa besar selain syirik, tidak mu'min tidak pula kafir, tetapi fasik, jadi kefasikan adalah suatu hal yang berdiri sendiri antara iman dak kafit. Tingkatan orang fasik di bawah orang mu'min dan di atas orang kafir. ${ }^{17}$

Menurut pandangan Mu'tazilah, pelaku dosa besar tidak dapat dikatakan mu'min secara mutlak. Karena keimanannya menurutnya adalah kepatuhan terhadap Tuhan, tidak cukup dengan pengakuan dan pembenaran. Berdosa besar bukanlah kepatuhan tapi kedurhakaan. Pelakunya tidak dapat dikatakan kafir secara mutlak, karena masi percaya kepada Tuhan, Rasul-Nya dan mengerjakan pekerjaan yang baik, hanya saja kalau meninggal sebelum bertaubatia dimasukkan kedalam neraka dan kekal didalamnya. Orang mu'min masuk syurga dan orang kafir masuk neraka, orang fasik pun dimasukkan ke neraka, hanya saja siksaannya lebih ringan dari pada orang kafir. ${ }^{18}$

Persoalan kafir mengkafirkan muncul pada pertikaian antara Ali Bin Abi Talib dan Muawiyah bin Abi Sufyan, mengenai khalifah yaitu siapa yang paling berhak menjadi khalifah diantara keduanya, faham Mu'tazilah berpendapat bahwa Ali Bin Abi Thalib, Muawiyah bin Abi
Sufyan, Abu Musa Al-Asy'ari, dan Amru bin Ash, kesemuanya itu adalah Fasik.

5) Amar ma'ruf nahi mungkar (perintah kebaikan dan melarang kejahatan). Prinsip ini lebih banyak berhubungan dengan taklif dan lapangan fiqih daripada lapangan tauhid. $^{19}$

Di zaman modern dan kemajuan ilmu pengetahuan dan teknologi, ajaran-ajaran $\mathrm{Mu}$ 'tazilah yang bersifat rasional itu telah mulai muncul kembali di kalangan umat Islam terutama di kalangan kaum terpelajar. Secara tak sadar mereka telah mempunyai paham-paham yang sama atau dekat dengan ajaran-ajaran Mu'tazilah. Mempunyai pahampaham yang demikian tidaklah membuat mereka ke luar dari Islam.

\section{PENUTUP}

Secara harfiah Mu'tazilah adalah berasal dari i'tazila yang berarti berpisah. Aliran Mu'tazilah muncul di Basrah, Irak pada abad 2 H. Kelahirannya bermula dari tindakan Wasil bin Atha (700-750 M), berpisah dari gurunya Imam Hasan al-Basri karena perbedaan pendapat. Wasil bin Atha berpendapat bahwa muslim yang berdosa besar bukan mu'min dan bukan kafir, berarti ia adalah fasik.

Mu'tazilah dengan aliran 
teologi Islam lainnya adalah pemahamannya yang lebih banyak mempergunakan dalil-dalil rasional dan bersifat filosofis. Sehingga wajar bila Mu'tazilah dikenal sebagai pengusung teologi rasional. Mereka lebih meninggikan kedudukan akal ketimbang wahyu. Dalam memahami Al-Qur'an pun mereka meninggalkan arti harfiah teks. Mereka hanya mengambil makna simbol teks dengan metode $t a$ 'wīl

$$
\text { Aliran Mu'tazilah yang }
$$
bercorak rasional yang cenderung liberal, ini mendapat tantangan keras dari kelompok tradisional Islam, terutama golongan Hambali, pengikut mazhab Ibn Hanbal. Sepeninggal al-Ma'mun pada masa Dinasti Abbasiyah tahun 833 M, Syiar Mu'tazilah berkurang, bahkan berujung pada dibatalkannya sebagai mazhab resmi negara oleh Khalifah alMutawakkil pada tahun $856 \mathrm{M}$

\section{Catatan Akhir:}

${ }^{1}$ Tahkim merupakan bentuk perdamaian untuk mereka yang berselisih dengan membentuk sebuah dewan atau majelis sidang yang diwakili masing-masing pihak yang bertikai.

${ }^{1}$ Ahmad Sahidin, 'Aliran-'Aliran dalam Islam (Cet. I; Bandung: PT. Salamadani Pustaka Semesta, 2009), h. 5.

${ }^{1}$ Mereka adalah penghafal Al-Qur'an dan orang-orang Badawi yang baru masuk Islam.

${ }^{1}$ Ahmad Hanafi, Theologi Islam (Ilmu Kalam), (Cet. IV; Jakarta: Bulan Bintang, 1982), h. 44.

${ }^{1}$ Harun Nasution, Teologi Islam AliranAliran Sejarah Analisa Perbandingan (Cet. V;
Jakarta: Universitas Indonesia (UI-Press), 2011), h. 40 .

${ }^{1}$ Ibid., h. 40.

${ }^{1}$ K.H.M. Thaib Thahir Abd. Mu'in, Ilmu Kalam, (Cet. VII; Jakarta: Widjaya, 1986), h. 102.

${ }^{1}$ Sahilun A. Nasir, Pemikiran Ilmu Kalam (Teologi Islam) Sejarah, Ajaran, dan Perkembangannya, op.cit., h. 163.

${ }^{1}$ Munawir Sjadzali, Islam dan Tata Negara Ajaran, Sejarah dan Pemikirannya, op.cit., h. 218.

${ }^{1}$ Ibid., h. 218.

${ }^{1}$ Ahmad Sahidin, 'Aliran-'Aliran dalam Islam, op.cit., h. 42.

${ }^{1}$ Ahmad Sahidin, 'Aliran-'Aliran dalam Islam, ibid., h. 220.

1 Harun Nasution, Teologi Islam AliranAliran Sejarah Analisa Perbandingan, Op.cit, h. 52-53. Lihat Ahmad Hanafi, Theologi Islam (Ilmu Kalam), )p.cit, h. 61.

${ }^{1}$ Al-Syahrastani, op. cit., hlm. 46-49

1 Abd Al Jabbar bin Ahmad, Syarah AlUshul Al-Khamzah, (Maktab Wahbah, Kairo, 1965), h. 2017.

1 Kementerian Agama RI Direktorat Jenderal Bimbingan Masyarakat Islam Derektorat Agama Islam Dan Pembinaan Syariah Islam, Al-Qur'an dan Terjemahnya, (Jakarta; Pt. Sinergi Pustaka Indonesia, 2012), h. 694.

${ }^{1}$ Ahmad Hanafi, Theologi Islam (Ilmu Kalam), Op.cit., h. 50.

1 Tosihiko Izutzu. Konsep Kepercayaan dalam Teologi Islam. Terjemahan. Agus Fahri Husein dkk (Cet.I; Yokyakarta: Tiara Wacana 1994), h.53.

\section{DAFTAR PUSTAKA}

Al-Qur'anul Karim

A. Nasir, Sahilun, Pemikiran Ilmu Kalam (Teologi Islam) Sejarah, Ajaran, dan Perkembangannya.

Ahmad, Muhammad, Tauhid Ilmu Kalam, Cet. I; Bandung: CV Pustaka Setia, 1998. 
Abd. Mu'in, K.H.M. Thaib Thahir Ilmu Kalam, Cet. VII; Jakarta: Widjaya, 1986.

Abd Al Jabbar bin Ahmad, Syarah AlUshul Al-Khamzah, (Maktab Wahbah, Kairo, 1965

Hasbi Ash Shiddieqy, Teungkum Muhammad, Sejarah dan Pengantar Ilmu Tauhid/Kalam, Cet. I; Semarang: PT Pustaka Rizki Putra, 1999.

Hanafi, Ahmad, Theologi Islam (Ilmu Kalam), Cet. IV; Jakarta: Bulan Bintang, 1982.

Izutzu. Tosihiko, Konsep Kepercayaan dalam Teologi Islam. Terjemahan. Agus Fahri Husein dkk (Cet.I; Yokyakarta: Tiara Wacana 1994.

Kementerian Agama RI Direktorat Jenderal Bimbingan Masyarakat Islam Derektorat Agama Islam Dan Pembinaan Syariah Islam, $\mathrm{Al}$ Qur'an dan Terjemahnya, Jakarta; Pt. Sinergi Pustaka Indonesia, 2012. Nasution, Harun, Teologi Islam AliranAliran Sejarah Analisa Perbandingan, Cet. V; Jakarta: Universitas Indonesia (UI-Press), 2011.

Teologi Islam Rasional, Cet. III; Ciputat: PT. Ciputat Press, 2005.

Rosak, , Abdul, Anwar, Rosihon, Ilmu Kalam, Cet. III: Bandung: CV. Pustaka Setia, 2012.

Sahidin, Ahmad, 'Aliran-'Aliran dalam Islam. Cet. I; Bandung: PT. Salamadani Pustaka Semesta, 2009. Sjadzali, Munawir Islam dan Tata Negara Ajaran, Sejarah dan
Pemikirannya.

Kementerian Agama RI Direktorat Jenderal Bimbingan Masyarakat Islam Derektorat Agama Islam Dan Pembinaan Syariah Islam, $A l$ Qur'an dan Terjemahnya, Jakarta; Pt. Sinergi Pustaka Indonesia, 2012. 